\title{
Recourse to Complementary/Alternative Medicine (CAM) at Times of Economic Crisis: The Case of Italy
}

\author{
Mara Tognetti \\ Department of Sociology and Social Research, University of Milano-Bicocca, Milano, Italy \\ Email: mara.tognetti@unimib.it
}

How to cite this paper: Tognetti, $M$. (2017) Recourse to Complementary/Alternative Medicine (CAM) at Times of Economic Crisis: The Case of Italy. Open Journal of Social Sciences, 5, 370-386. https://doi.org/10.4236/jss.2017.57023

Received: June 14, 2017

Accepted: July 22, 2017

Published: July 25, 2017

Copyright $\odot 2017$ by author and Scientific Research Publishing Inc. This work is licensed under the Creative Commons Attribution International License (CC BY 4.0).

http://creativecommons.org/licenses/by/4.0/ (c) (i) Open Access

\begin{abstract}
The economic crisis that has invested western countries in the last years has determined a significant reduction in consumption of medication and treatments recourse, too. The Economic recession is generally accompanied by a decrease in health-related consumption, varying according to the welfare model, and especially affecting people of working age with a low income. The present paper focuses on the effects of the economic crisis on users of Complementary/Alternative Medicine treatments (from now on referred as CAM). Based on multi-purpose data analyses, this work aims to examine what kind of strategies such consumers have adopted in order not to neglect their health despite feeling the economic pinch. Our analyses are principally based on ISTAT, Italian National Institute for Recording Statistics findings. Specifically, our research is based on the survey "Health conditions and recourse to health services". The analysed data refer to the Italian context in the period comprised from 2000 to 2013. The results of this work reveal how, in this delicate phase of the economy, traditional consumers of CAM have signally reduced their use of such treatments. In Italy, in the observed period, factors as working status, age, smoking and chronic diseases have been determinant in the decision to use CAM. The article suggests that, where health is at stake, CAM users are more strategic than the average biomedicine users. Furthermore, confirming the past trend, it shows how difficult it is to afford forms of treatment not covered by the health system as well as it underlines the lack of data for comparison with other countries.
\end{abstract}

\section{Keywords}

Complementary/Alternative Medicine (CAM), Crisis, Healthcare Behaviour, Health Inequalities, Health Systems 


\section{Introduction}

Since individuals' economic position has a great influence on both health and health seeking behaviours [1] [2] [3], the latter could be considered a sensitive yardstick of the changes in both people's socio-economic condition/cultural capital and in the background context.

As pointed out by many international scholars, the economic crisis was triggered by the collapse of American banks in 2008, and thereafter spreads to Europe and Italy, has had a distinctly adverse effect on health-related consumption, causing prevention (such as dental care) to fall off markedly.

The crisis also means that fewer people are taken on or taken back to work after losing their job because of serious illness. The situation becomes still worse when the pathology is mental, or involves disabilities, etc. [4] [5].

Besides producing impoverishment via illness and health outlay, the recession has also had a direct effect on triggering illness, as well as changing lifestyles and health styles simply through curtailing income. Further the short-term effects mentioned, there are long-term consequences, which have been hardly reckoned yet [2] [6].

The adverse impact of the economic crisis on health is largely bound up with the increasing of unemployment, instability and precariousness of jobs, leading to unhealthy lifestyles and reluctance to apply for medical assistance. As already noted, [1] [7] when there is no effective safety nets or protection of social capital, the poor and most vulnerable people are those who bear the brunt of the crisis in the short and long term [8] [9].

Recourse to primary care has fallen by $19.5 \%$ in the United States, $6.6 \%$ in France and 3.6\% in Germany. It has remained stable in Great Britain and Canada. Even those insured tend to put off prescribed intervention to avoid the burden of participation. What most commonly shelved are elective surgery and screening. Purchase of medicines is likewise curbed [10]. Another risk factor comes from limited access to, and inappropriate use of, welfare services, while a shift can be detected from private to public services. This pattern has been well documented in Greece [11].

The economic crisis has continued to bear heavily on Italy lately and this has involved health: 2012 has been a particularly affected year, in which the crisis effects on health were significantly felt, in terms of reduction in consumption of medication, dental check-ups, examinations by specialists [12].

Thus, in order to investigate what happened before and during the crisis, it is crucial to analyse healthcare behaviours, including the recourse to Complementary/Alternative Medicine (CAM) [13].

In general terms, we can consider this kind of Medicine as "complementary" to biomedical therapies. Typical it is the case of the homeopathic treatments used for reducing the side effects of the chemotherapy.

We can also solve a health problem exclusively using CAM. In this case, we can point them out as "alternative" medicine, for instance, in the particular case of the migrain. 
In legal terms, CAM in Italy are identified as medical treatments and health therapies normally practiced by doctors which obtained a formal legitimation from their Legal Order. In the last seven year, the number of doctors who practice CAM in Italy increased almost by $180 \%$.

Furthermore, in Italy CAM refers to treatments are not falling under the National Health Service. Nowadays only the Region of Tuscany [14] admits certain forms of CAM under its Regional Health Service (homeopathy, phytotherapy, acupuncture).

In this matter, people pay for such treatments out of their own pockets, unless they have supporting health insurance. This latter issue makes interesting to analyse CAM consumption figures and to observe the impact of the crisis on health behaviours.

Analysis of CAM trends thus serves as a marker of the population at large but it revels to be particular useful for describing the middle classes who have been hard hit by the ongoing crisis [15]. The literature has long highlighted the adverse impact of economic hardship on people's health. The effects are numerous and contradictory [16] [17]. In Italy, for example, it is the middle and upper middle classes that resort to CAM for their health, and also those with high cultural capital.

In the table below, data show the changes related to consumption of CAM by people between the end of last century and the beginning of this, as shown in Table 1. The meanings of acronyms quoted in the table below are the followings: ABACUS, Istituto Europeo di Ricerca Studio e Formazione (European Institute of Research Study and Training); CENSIS, Centro Studi Investimenti Sociali (Center for Social Investment Study); DOXA, Ricerche e Analisi di Mercato (Research and Market Analysis Company); DOXAFARMA, Ricerche di mercato farmaceutiche e per la salute (Pharmaceutical Market and Public Health Research Company); EURISPES, Istituto di Studi Politici Economici e Sociali (Institute of Political Economic and Social Studies); FORMAT, Istituto di ricerca (Research Institute); ISPO, Istituto per gli Studi sulla Pubblica Opinione (Institute for Public Opinion Studies); ISTAT, Istituto Nazionale di Statistica (Italian National Institute for Recording Statistics).

The analysis gains further interest if we bear in mind the World Health Organization (WHO) recommendation that using traditional medicines and CAM reduces the health burden of various countries. From that analysis, importantly, it emerges how CAM fulfill a new demand for individual wellbeing, as well as health needs. They offer a symbolic response to the health issue, not necessarily in terms of effectiveness, as Melucci points out [18]. The revival of traditional medicines and the burgeoning use of CAM meet a cultural need as well. Their focus is person-centred and is about fulfillment in society; they make people take more direct responsibility for their own health [19]. Illness is seen as a breach of harmony, an interaction with the cosmic process in a holistic light, and not as mere organ dysfunction. CAM respond to new health requirements (the underlying system of humanistic and spiritual values), emphasizing the person's self- 
Table 1. Consumption of CAMs in Italy.

\begin{tabular}{|c|c|}
\hline Statistical Source and Year of Reference & Incidence of Recourse \\
\hline ISTAT (1996-99) & 9 million Italians use CAM ( $15.5 \%$ of the population). \\
\hline ABACUS (2003) & $30.0 \%$ of Italians are familiar with the term Non-Conventional Medicines (CAM). \\
\hline DOXA (2003) & $23.0 \%$ of the population use CAM. \\
\hline ISPO (2003) & $\begin{array}{l}65.0 \% \text { of the population is familiar with the term Non-Conventional Medicines (CAM) } \\
\text { and know about them. }\end{array}$ \\
\hline FORMAT (2003) & $31.7 \%$ of Italians have used CAM at least once; $23.4 \%$ use them regularly. \\
\hline CENSIS (2003) & $\begin{array}{l}50.0 \% \text { of Italians consider CAM useful; over } 70.0 \% \text { are in favor of their being refunded } \\
\text { by the National Health System; } 65.0 \% \text { would like more control over them by the National } \\
\text { Health Service. }\end{array}$ \\
\hline Menniti-Ippolito et al. (2004) & $\begin{array}{l}15.6 \% \text { of Italians use CAM (Homeopathy } 8.2 \% \text {, Manual Therapies } 7 \% \text {, Phytotherapy } \\
4.8 \% \text {, Acupuncture } 2.9 \% \text {, another kind of treatments } 1.3 \% \text { ). }\end{array}$ \\
\hline ISTAT (2005) & 8 million Italians use CAM ( $13.6 \%$ of the population). \\
\hline EURISPES (Rapporto Italia 2006) & $10.6 \%$ of the population choose CAM. \\
\hline $\begin{array}{l}\text { Osservatorio Scienza Tecnologia e Società, under } \\
\text { the Centro Ricerche Observa-Science in Society, } \\
\text { published as Nova in Il Sole } 24 \text { ore ( } 24 \text { 07.12.2006) }\end{array}$ & $\begin{array}{l}\text { One Italian in three at least occasionally uses homeopathic products to treat their } \\
\text { problems. }\end{array}$ \\
\hline CENSIS (2008) & $\begin{array}{l}23.4 \% \text { have used CAM in the course of the last year (especially Homeopathy and } \\
\text { Phytotherapy). }\end{array}$ \\
\hline EURISPES (Rapporto Italia 2010) & Over 11 million opt for CAM treatments (18.5\% of the population). \\
\hline $\begin{array}{l}\text { Health Monitor CompuGroup Medical-Il Sole } 24 \\
\text { Ore Sanità (2011) }\end{array}$ & $\begin{array}{l}\text { Around } 52.0 \% \text { of general practitioners recommend their patients to use homeopathic } \\
\text { medicines. }\end{array}$ \\
\hline EURISPES (Rapporto Italia 2012) & $14.5 \%$ of the population resort to CAM. \\
\hline DOXAFARMA (May 2012) & $\begin{array}{l}82.5 \% \text { say they have heard of homeopathic medicines; } 16.2 \% \text { have used them at least } \\
\text { once in the last year. }\end{array}$ \\
\hline $\begin{array}{l}\text { ISTAT "Tutela della salute e accesso alle cure. The } \\
\text { year 2013." (published } 11 \text { July 2014b) }\end{array}$ & $\begin{array}{l}\text { Recourse to CAM has dropped by half since } 2000 \text {, from } 15.8 \% \text { to } 8.2 \% \text {. Use of } \\
\text { homeopathic remedies fell from } 7.0 \% \text { to } 4.1 \% \text { between } 2005 \text { and } 2013 \text {. }\end{array}$ \\
\hline EURISPES (Rapporto Italia 2017) & Recourse to CAM has increased from $14.5 \%$ to $21.2 \%$. \\
\hline
\end{tabular}

Source: adjusted from Advanced Therapies, 2, 2013.

responsibility for his/her own health.

That is particularly important in the case of a chronic disease, the long duration of which turns them into existential experiences, at least in the last phase of the individual's life. But although such practices are in line with the latest thinking on individual health, they have not met with general recognition, at least by the Italian regional health authorities [14]. The next section will examine the methodology adopted to analyze the official data related to the consumption of CAM in Italy. The most important results emerged will be widely discussed too.

\section{Methods}

We mainly based our study on the data gathered by ISTAT (Italian National Institute for Recording Statistics) using multipurpose survey named "Condizioni di salute e ricorso ai servizi sanitari". The survey is part of the System of Multipurpose Surveys on families started in 1993 and was repeated almost every five 
years. The last edition of the survey has been conducted by ISTAT in the months of September and December 2012, March and June 2013. We referred to the data comprised in the period from 2000 to 2013.

The survey, by gathering information directly from the citizens, provided us useful data to investigate the public's relationship with health services and the use of non-conventional therapies.

According to literature, the analysis was undertaken from an empirical perspective. The analysis was performed considering demographics in order to get a sense of the changes occurred. Data were analysed using SPSS (SPSS Inc., Chicago, IL, USA) and descriptive statistics (frequency, percentage).

We started analyzing the incidence of the recourse to CAM treatments in Italy during the last years.

We continued analyzing the trend more closely with special reference to three different kinds of CAM therapies people had recourse to in the period observed: acupuncture, homeopathy or phytotherapy, pointing out the consumption trend for each of the most used therapies in the last 10 years by the Italian people.

Subsequently, we provide a statistical analysis of the changes occurred in CAM consumption related to the demographics of people interviewed.

According to the data, we also tried to observe attitudes and behaviors related to their academic qualifications. The aim was to define the relationships existing between the purchasers' choices and their cultural capital level.

In the last part of the paper, we tried to define a spatial profile of the CAM users in Italy. Analysis addressed both the coverage of CAM treatments in the different regional healthcare systems and equity issues on patient healthcare access. The analysis aimed at testing patient preferences and trend of consumption for different kind of CAM treatments according to the geographical area they live in.

As mentioned in the previous paragraph, MNC treatments are not included among the services provided by the Italian National Health System. In order to their particular nature, a related price list does not exist. So was not been possible to affect some kind of analysis about this particular aspect.

\section{Results}

When individuals or families fall sick in time of economic crisis, the challenge of coping with the disease may be a tough one, economically and socially. The data [4] suggest that they often cut back on treatment and seeing health professionals: thus in Italy $2014,14.2 \%$ of the people gave up going to the dentist, and the figure rises to $32.3 \%$ if one only considers the low-income bracket [20].

Thus, in periods of economic crisis, the whole issue of sustainability of the health budget is seriously reviewed both by public decision-makers and by individuals/families.

Families belonging to low-income brackets confine their expenditure to non-compressible (i.e. primary) health goods, like purchasing medicines and seeing specialists. Families from the highest brackets, by contrast, favour "lux- 
ury" health treatment (prosthetics, devices, dentistry, etc.). Thus, there is a serious risk during the crisis that individuals and families get impoverished by their health requirements [21].

Research and surveys carried out in Italy on the consumption of CAM show a steady rise in time, beginning from the early Nineties until 2005, when it involved $13.6 \%$ of the population. The trend then inverted slumped to $8.2 \%$ in 2013 [22].

A first analysis clearly suggests that the drop in consumption coincided with the central years of the economic crisis. However, we need to analyse the trend more closely to understand who and what kind of individual displayed this new behaviour.

In analysing the historical trend in CAM consumption in Italy, with special reference to acupuncture, homeopathy, and phytotherapy, as shown in Figure 1, we note that from 1991 to 2000 use of CAM in Italy rose steadily. The consumption then slowly decreased from $8.2 \%$ in 2000 to $7.0 \%$ in 2007 in the case of homeopathy. Phytotherapy followed the same pattern, going from $4.8 \%$ to $3.7 \%$ in the same years, while acupuncture diminished from $2.9 \%$ to $1.8 \%$. A slight fall, but systematic.

In the case of manual treatments, although we do not possess the data to reconstruct the historical profile from 2005 to 2013, the same trend was followed: from $6.4 \%$ in 2005 the figure drops to $3.5 \%$ in 2013.

Although the downward trend in CAM began a few years (two) before the economic crisis, our data show that it had a markedly adverse effect on the consumer pattern. During the exact period of recession, recourse to CAM underwent a steep decline, exceeding the previous trend recorded between 2000 and 2005.

Men, in particular, cut back much more than women: in 2000, $12.9 \%$ of men had recourse to CAM, while the figure for 2013 was only $6.8 \%$. Though women's consumption did reduce in the period considered, women continued to use

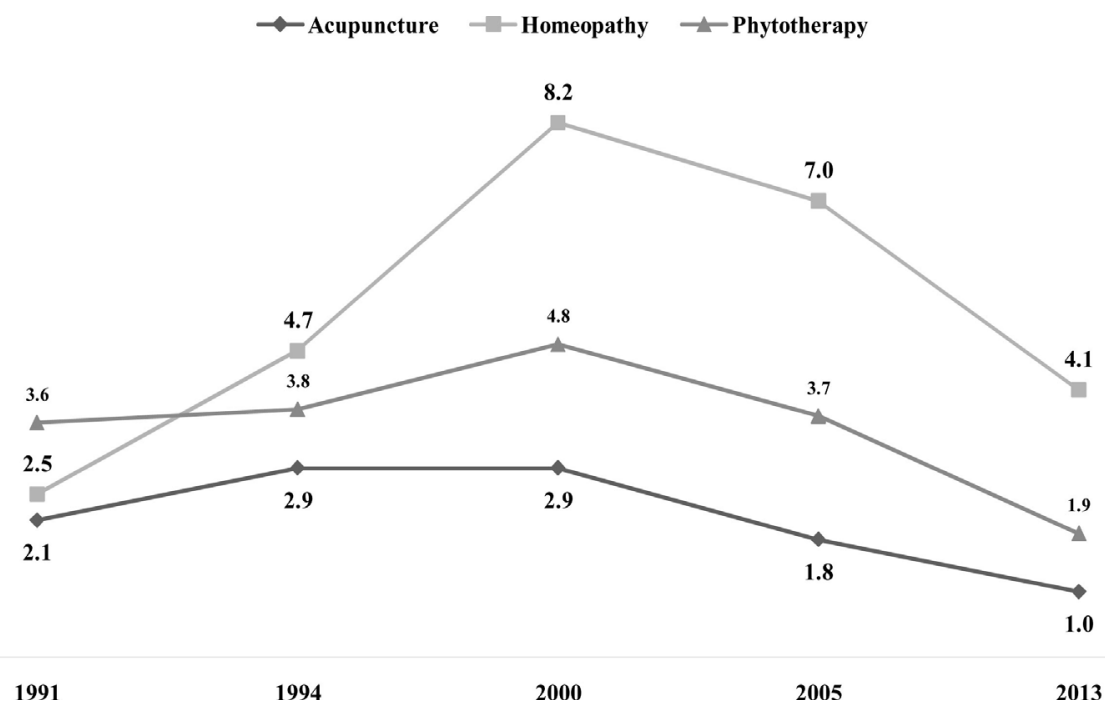

Figure 1. Recourse to non-conventional (CAM) therapies. 


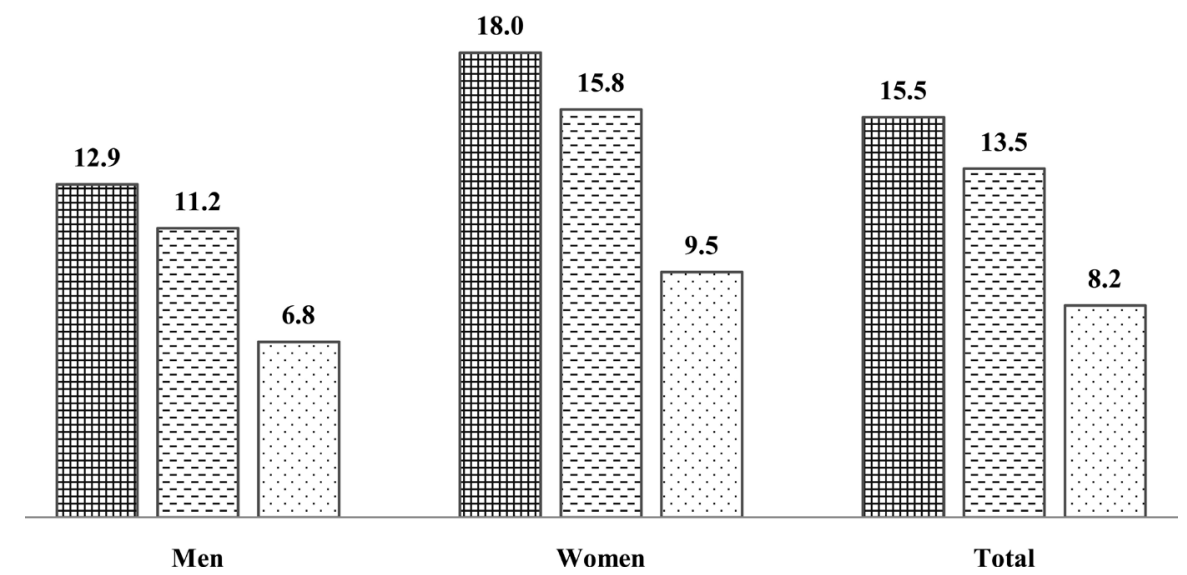

Figure 2. Recourse to non-conventional (CAM) therapies.

CAM in the crisis period, and if less than before, nonetheless more than men. In 2000 they stood at $18.0 \%$; in 2013 the figure was $9.5 \%$.

Over the period in question, there was thus roughly a halving of consumption, as shown in Figure 2, but one notes a gender difference.

On closer inspection of the CAM-using population in relation to age and gender, we note the greatest diminution by women using homeopathy: their consumption falls from $10.1 \%$ in 2000 to $8.8 \%$ in 2005 , then dropping to $5.0 \%$ in 2013 , a reduction by no less than $3.8 \%$. Next, it comes manual treatments, which go from $7.7 \%$ in 2000 to $7.1 \%$ in 2005 , and then $3.9 \%$ in 2013 , which is a decline by 3.2 percentage points. The greatest decline by men is in use of manual treatments, which reduce from $6.3 \%$ in 2000 to $5.7 \%$ in 2005 and then $3.1 \%$ in 2013 , i.e. a reduction by $2.6 \%$.

To a lesser degree, the use of phytotherapy follows the same downward trend. Between 2005 and 2013, women's consumption drops by 2.5\%, and men's by $1.2 \%$. Acupuncture falls off, too, though to a lesser extent than phytotherapy: for women, it is minus $1.0 \%$, for men minus $0.7 \%$.

Consumption of other non-conventional therapies declines much less over the same period $(-0.1 \%$ for men and $-0.2 \%$ for women). Age-wise, it is women in the 35 - 44 bracket, which cut down their use in the 2005-2013 period, the drop is $6.7 \%$. The 25 - 34 year-olds are the next to reduce, their figure being $6.4 \%$. Women in the last age bracket also cut down on manual treatments more than do men, the reduction being 5.4 percentage points.

The biggest reduction for men is among manual treatment users aged between 45 and $54(-4.4 \%)$, followed by the $35-44$ year-old whose consumption drops by $4.3 \%$.

In general, it is women between 35 and 45 years of age who cut down their outlay on CAM. For men, the same occurs with the 45 - 54 age bracket. It is thus age rather than gender that bears on CAM consumption, and the greatest reduction regards people in the central bracket of their lifespan. Manual treatments record the greatest falling off. 
Let us now consider academic qualifications which are known to be an important gauge of healthcare consumption in general, [1] especially CAM. In Table 2, data in rows " $\mathrm{D}$ " are obtained from the difference of the values for the years 2013 and 2005.

The data available show how the biggest drop in CAM consumption is generally found among graduates and those with school diplomas. The greatest contraction of all occurs with highly qualified women. In the case of homeopathy, they reduced their consumption from 2005 to 2013 by 5.8 percentage points, followed by those with only a middle-school diploma who dropped by 5.4 percentage points in the same period, again concerning CAM. We should remember here that this was the part of population that normally made great use of CAM, until the crisis.

In the period we are focusing on, women's consumption of phytotherapy contracts by 3.7 percentage points (both for graduates and middle-school attenders). Again among women, the decline in the use of manual treatments is 4.8 percentage points.

Over the same timespan, men's consumption of homeopathy taper off those from university education (minus 3.5 percentage points) and those from the middle school bracket, though to a lesser percentage (minus 2.4 percentage points). The reduction in phytotherapy consumption by men graduates/high school diploma-bearers is 1.7 percentage points.

Focusing on those who only possess a middle-school diploma, it is once again women who cut down their CAM consumption, more than men (5.4 percentage points less for women using homeopathy, versus 2.4 percentage points for men). In the case of phytotherapy, the decrease among women is 3.7 percentage points, among men 1.4 percentage points. Manual treatments fall off by $4.5 \%$ (women) and $3.4 \%$ (men).

If we now look at the CAM consumption trend for 2005-2013 in relation to professional status, as expected the greatest drop occurs in men who have precarious job contracts (the Co.Co.Co-Collaborazione Coordinata e Continuativa, lit. Coordinate and Continuative Collaboration, and Co.Co.Pro-Collaborazione Coordinata a Progetto', lit. Collaboration into the framework of a project, which are the most diffused precarious contractual forms in the panorama of the Italian job market) where homeopathy falls by 5.2 percentage points, phytotherapy by 2.7 percentage points, manual treatments by 6.4 percentage points and 0.7 percentage points for other forms of CAM.

As for homeopathy, the main drop in consumption was among the workdisabled: 2.3 percentage points. A sharp decrease in CAM use is found over the same period among managers, entrepreneurs and freelance professionals, only just behind those on the Co.Co.Co. Contract scheme in terms of reduced consumption. We also find a 5.7 percentage points decrease affecting manual treatments, a 3.3 percentage points reduction for homeopathy, minus 2.2 percentage points for phytotherapy and minus 1.0 percentage point for acupuncture, while the other CAMs fell by 0.4 percentage point. It is thus evident that those in pre- 
Table 2. Consumption of non-conventional (CAM) therapies grouped by academic qualifications.

\begin{tabular}{|c|c|c|c|c|c|}
\hline MEN & \multirow[b]{2}{*}{ Year } & \multicolumn{4}{|c|}{ Academic Qualification } \\
\hline Kind of Treatment & & $\begin{array}{c}\text { University Degree } \\
\text { and High School } \\
\text { Diploma }\end{array}$ & $\begin{array}{c}\text { Junior } \\
\text { High School } \\
\text { Certificate } \\
\end{array}$ & $\begin{array}{c}\text { Primary School } \\
\text { License and } \\
\text { No Qualification }\end{array}$ & Total \\
\hline \multirow[t]{4}{*}{ Acupuncture } & 2000 & 3.1 & 2.5 & 1.8 & 2.5 \\
\hline & 2005 & 1.9 & 1.6 & 1.1 & 1.5 \\
\hline & 2013 & 1.1 & 0.7 & 0.4 & 0.8 \\
\hline & $\mathrm{D}$ & -0.8 & -0.9 & -0.7 & -0.7 \\
\hline \multirow[t]{4}{*}{ Homeopathy } & 2000 & 9.0 & 5.5 & 3.8 & 6.0 \\
\hline & 2005 & 7.0 & 4.3 & 3.3 & 4.9 \\
\hline & 2013 & 3.5 & 1.9 & 2.6 & 2.8 \\
\hline & $\mathrm{D}$ & -3.5 & -2.4 & -0.7 & -2.1 \\
\hline \multirow[t]{4}{*}{ Phytotherapy } & 2000 & 5.4 & 3.5 & 2.5 & 3.8 \\
\hline & 2005 & 3.6 & 2.5 & 1.7 & 2.6 \\
\hline & 2013 & 1.9 & 1.1 & 1.1 & 1.4 \\
\hline & $\mathrm{D}$ & -1.7 & -1.4 & -0.6 & -1.2 \\
\hline \multirow[t]{4}{*}{ Manual Treatments } & 2000 & 9.1 & 6.9 & 3.8 & 6.6 \\
\hline & 2005 & 8.1 & 6.4 & 3.3 & 6.0 \\
\hline & 2013 & 4.2 & 3.0 & 1.7 & 3.2 \\
\hline & $\mathrm{D}$ & -3.9 & -3.4 & -1.6 & -2.8 \\
\hline \multirow[t]{4}{*}{ Another Kind of Treatments } & 2000 & 1.5 & 1.2 & 0.7 & 1.1 \\
\hline & 2005 & 0.5 & 0.3 & 0.2 & 0.4 \\
\hline & 2013 & 0.2 & 0.1 & 0.2 & 0.2 \\
\hline & $\mathrm{D}$ & -0.3 & -0.2 & 0.0 & -0.2 \\
\hline \multicolumn{6}{|l|}{ WOMEN } \\
\hline \multirow[t]{4}{*}{ Acupuncture } & 2000 & 4.8 & 3.5 & 2.6 & 3.5 \\
\hline & 2005 & 2.9 & 2.2 & 1.7 & 2.3 \\
\hline & 2013 & 1.7 & 1.0 & 0.9 & 1.3 \\
\hline & $\mathrm{D}$ & -1.2 & -1.2 & -0.8 & -1.0 \\
\hline \multirow[t]{4}{*}{ Homeopathy } & 2000 & 17.4 & 10.6 & 4.9 & 10.2 \\
\hline & 2005 & 13.6 & 8.9 & 4.6 & 8.8 \\
\hline & 2013 & 7.8 & 3.5 & 2.3 & 5.0 \\
\hline & $\mathrm{D}$ & -5.8 & -5.4 & -2.3 & -3.8 \\
\hline \multirow[t]{4}{*}{ Phytotherapy } & 2000 & 9.7 & 6.6 & 3.4 & 6.2 \\
\hline & 2005 & 7.4 & 5.1 & 2.8 & 5.0 \\
\hline & 2013 & 3.7 & 1.4 & 1.4 & 2.4 \\
\hline & $\mathrm{D}$ & -3.7 & -3.7 & -1.4 & -2.6 \\
\hline \multirow[t]{4}{*}{ Manual Treatments } & 2000 & 11.6 & 8.1 & 5.7 & 8.1 \\
\hline & 2005 & 10.5 & 7.6 & 4.7 & 7.5 \\
\hline & 2013 & 5.7 & 3.1 & 2.7 & 4.1 \\
\hline & $\mathrm{D}$ & -4.8 & -4.5 & -2.0 & -3.4 \\
\hline \multirow[t]{4}{*}{ Another Kind of Treatments } & 2000 & 2.3 & 1.6 & 0.9 & 1.5 \\
\hline & 2005 & 0.7 & 0.5 & 0.2 & 0.4 \\
\hline & 2013 & 0.3 & 0.2 & 0.2 & 0.3 \\
\hline & $\mathrm{D}$ & -0.4 & -0.3 & 0.0 & -0.1 \\
\hline
\end{tabular}


Table 3. Consumption of non-conventional (CAM) therapies grouped by place of residence.

\begin{tabular}{cccccccccccccccccc}
\hline & \multicolumn{3}{c}{ Acupuncture } & \multicolumn{3}{c}{ Homeopathy } & \multicolumn{3}{c}{ Phytotherapy } & \multicolumn{3}{c}{ Manual treatments } & \multicolumn{2}{c}{ Another Kind of Treatments } \\
\hline Geographical Area & 2000 & 2005 & 2013 & 2000 & 2005 & 2013 & 2000 & 2005 & 2013 & 2000 & 2005 & 2013 & 2000 & 2005 & 2013 \\
North-West & 3.8 & 2.4 & 1.2 & 11.4 & 10.2 & 4.9 & 5.9 & 4.7 & 2.0 & 9.2 & 8.4 & 4.5 & 1.6 & 0.5 & 0.3 \\
North-East & 4.0 & 2.6 & 1.5 & 13.1 & 11.4 & 6.9 & 8.6 & 6.7 & 2.9 & 10.7 & 10.7 & 5.1 & 1.8 & 0.7 & 0.4 \\
Central & 3.0 & 2.0 & 1.2 & 8.2 & 6.8 & 4.9 & 4.7 & 3.6 & 2.3 & 7.4 & 6.3 & 3.7 & 1.4 & 0.3 & 0.2 \\
South & 1.3 & 1.0 & 0.5 & 2.6 & 2.0 & 1.1 & 1.8 & 1.3 & 0.9 & 3.0 & 2.6 & 1.7 & 0.6 & 0.2 & 0.1 \\
Islands & 1.9 & 1.0 & 0.5 & 4.7 & 3.4 & 2.1 & 3.0 & 2.1 & 1.2 & 4.0 & 3.0 & 1.7 & 0.7 & 0.2 & 0.1 \\
Italy & 2.9 & 1.8 & 1.0 & 8.2 & 7.0 & 4.1 & 4.8 & 3.7 & 1.9 & 7.0 & 6.4 & 3.5 & 1.3 & 0.4 & 0.2 \\
\hline
\end{tabular}

carious jobs reduce their CAM consumption most. The same contraction, can be noted, also affects entrepreneurs and the freelance.

In the case of female subjects, the reduction in CAM consumption in relation to professional status proves to be less linear than is found with men.

In general, the statistics show that those belonging to the middle classes have most felt the weight of the economic crisis in Italy as well as elsewhere [15] [23]. This hardship is borne out by consumption of health services/products, especially CAM, which are not supported by the National Health Service in Italy.

In terms of geographical distribution, the Italian population differs widely with regard to CAM [14], a pattern that is still found during the economic crisis, as shown in Table 3. The Italian regions comprised in each of the five geographical areas listed in the table below are the followings: Piemonte, Valle D’Aosta, Liguria, Lombardia (North-West); Trentino Alto Adige, Veneto, Friuli Venezia-Giulia, Emilia-Romagna (North-East); Toscana, Umbria, Marche, Lazio (Central) Abruzzo, Molise, Campania, Puglia, Basilicata, Calabria (South);Sicilia, Sardegna (Islands). The proposed groupings are those used by ISTAT in the elaboration and provision of national statistical data.

Consumers living in the northern regions have contracted their consumption the most: those in the north-eastern ones, in particular, have cut down hard on manual treatments (minus 6.2 percentage points), followed by those in the northwest who have spent 4.7 percentage points less on homeopathy.

Various kinds of CAM are often used together, as well as a combination of CAM and biomedicine. We analyse this behaviour pattern, again in relation to consumption in the years of economic crisis. As shown in Table 4, it is those who used 3 or more CAMs who reduced their consumption most, as we shall see later in the paper.

While those who used 3 or more CAMs reached $12.5 \%$ in 2000, the figure for 2005 falls to 9.7 percentage points and settles on 6.3 percentage points in 2013. A significant decrease, consumption has halved in the space of thirteen years. Those who used two CAMs again reduced their consumption, though to a lesser extent than multiple CAM users. Thus by 2000 those using 2 CAMs had reached 22.0 percentage points but dropped to 21.1 percentage points in 2005 and 18.4 percentage points in 2013. 
Table 4. Number of CAMs used grouped by age and gender.

\begin{tabular}{|c|c|c|c|c|c|c|c|c|c|}
\hline \multirow[b]{2}{*}{ Age Brackets } & \multicolumn{3}{|c|}{1 Kind of CAM Therapy } & \multicolumn{3}{|c|}{2 Kinds of CAM Therapy } & \multicolumn{3}{|c|}{3 Kinds of CAM Therapy } \\
\hline & Men & Women & Men \& Women & Men & Women & Men \& Women & Men & Women & Men \& Women \\
\hline & \multicolumn{9}{|c|}{2000} \\
\hline $0-14$ & 79.4 & 79.6 & 79.5 & 13.5 & 16.4 & 14.9 & 7.1 & 4.0 & 5.6 \\
\hline $15-24$ & 72.8 & 70.3 & 71.2 & 17.1 & 19.7 & 18.7 & 10.2 & 10.0 & 10.1 \\
\hline $25-34$ & 69.3 & 60.2 & 63.5 & 19.2 & 26.6 & 23.8 & 11.5 & 13.3 & 12.6 \\
\hline $35-44$ & 63.7 & 59.5 & 61.3 & 23.2 & 23.9 & 23.6 & 13.1 & 16.6 & 15.1 \\
\hline $45-54$ & 63.4 & 58.6 & 60.6 & 23.7 & 25.8 & 24.9 & 12.9 & 15.5 & 14.4 \\
\hline $55-64$ & 66.7 & 64.3 & 65.3 & 22.6 & 21.4 & 21.9 & 10.7 & 14.3 & 12.8 \\
\hline $65-69$ & 70.6 & 62.3 & 65.6 & 20.1 & 24.2 & 22.6 & 9.3 & 13.5 & 11.9 \\
\hline $70-74$ & 70.3 & 69.5 & 69.8 & 17.0 & 17.9 & 17.6 & 12.7 & 12.6 & 12.6 \\
\hline 75 and over & 68.7 & 72.9 & 71.6 & 21.0 & 16.9 & 18.1 & 10.2 & 10.2 & 10.2 \\
\hline \multirow[t]{2}{*}{ Total } & 68.1 & 63.7 & 65.5 & 20.6 & 22.9 & 22.0 & 11.3 & 13.4 & 12.5 \\
\hline & \multicolumn{9}{|c|}{2005} \\
\hline $0-14$ & 82.1 & 80.4 & 81.2 & 14.9 & 17.1 & 16.0 & 3.0 & 2.5 & 2.8 \\
\hline $15-24$ & 75.6 & 71.7 & 73.2 & 18.1 & 20.4 & 19.5 & 6.3 & 7.9 & 7.3 \\
\hline $25-34$ & 74.2 & 62.6 & 67.1 & 19.4 & 25.2 & 23.0 & 6.4 & 12.2 & 10.0 \\
\hline $35-44$ & 68.4 & 60.3 & 63.6 & 21.1 & 25.5 & 23.7 & 10.4 & 14.2 & 12.7 \\
\hline $45-54$ & 69.6 & 61.9 & 65.1 & 19.8 & 24.5 & 22.6 & 10.6 & 13.6 & 12.4 \\
\hline $55-64$ & 73.3 & 65.8 & 68.8 & 19.4 & 22.3 & 21.1 & 7.3 & 12.0 & 10.1 \\
\hline $65-69$ & 75.2 & 70.6 & 72.3 & 17.2 & 18.1 & 17.7 & 7.6 & 11.4 & 10.0 \\
\hline $70-74$ & 78.7 & 75.4 & 76.5 & 16.9 & 17.4 & 17.2 & 4.5 & 7.2 & 6.3 \\
\hline 75 and over & 80.4 & 73.6 & 75.9 & 16.5 & 18.2 & 17.6 & 3.1 & 8.2 & 6.5 \\
\hline \multirow[t]{2}{*}{ Total } & 73.6 & 66.2 & 69.2 & 18.9 & 22.6 & 21.1 & 7.5 & 11.2 & 9.7 \\
\hline & \multicolumn{9}{|c|}{2013} \\
\hline $0-14$ & 80.9 & 80.4 & 80.7 & 17.7 & 17.1 & 17.4 & 1.4 & 2.4 & 1.8 \\
\hline $15-24$ & 77.3 & 74.9 & 75.9 & 18.3 & 19.1 & 18.8 & 4.4 & 6.0 & 5.3 \\
\hline $25-34$ & 79.4 & 71.7 & 74.7 & 15.8 & 19.6 & 18.1 & 4.8 & 8.7 & 7.2 \\
\hline $35-44$ & 76.2 & 65.6 & 69.9 & 19.9 & 24.9 & 22.9 & 3.9 & 9.4 & 7.2 \\
\hline $45-54$ & 77.3 & 70.5 & 73.1 & 15.7 & 18.6 & 17.5 & 7.0 & 10.8 & 9.4 \\
\hline $55-64$ & 77.7 & 68.8 & 72.5 & 17.0 & 22.4 & 20.2 & 5.4 & 8.8 & 7.4 \\
\hline $65-69$ & 84.3 & 79.1 & 81.0 & 14.1 & 14.2 & 14.1 & 1.6 & 6.8 & 4.9 \\
\hline $70-74$ & 83.4 & 82.7 & 83.0 & 13.4 & 13.9 & 13.7 & 3.2 & 3.4 & 3.3 \\
\hline 75 and over & 85.3 & 82.0 & 82.9 & 11.6 & 14.2 & 13.4 & 3.2 & 3.8 & 3.6 \\
\hline Total & 79.0 & 72.8 & 75.3 & 16.8 & 19.4 & 18.4 & 4.2 & 7.7 & 6.3 \\
\hline
\end{tabular}


Over the same period, the number of people using one CAM alone rises, by contrast, from 65.5 percentage points in 2000 to 69.2 percentage points in 2005 and 75.3 percentage points in 2013. We may thus deduce that in a time of crisis multiple CAM-users contain their budget but do not completely give up CAM for their health, but just use fewer forms of it.

Use of two CAMs simultaneously again decreases more slowly among women than men: over the three years in question women's percentage points go from 22.9 to 22.6 and then 19.4. In men's case, the pattern is 20.6 in 2000, 18.9 in 2005 and 16.8 in 2013.

What does fall markedly in this bracket is the use of three CAMs simultaneously which goes from 5.6 percentage points in 2000 to 2.8 in 2005 and 1.8 in 2013.

\section{Discussion and Conclusions}

The main goal of the present work has been to analyze the effects of the crisis on health. Reflections emerging from the data suggest the negative influence of economic/financial insecurity upon individual health and health seeking behaviors. In particular, the effects of the economic crisis strike on health consumption whether on biomedicine treatments or CAM ones.

We conducted this study in order to gather some evidences from the Italian experience where the available data show a drop in a family per capita health spending by $5.5 \%$ between 2008 and 2009 .

The behaviors related to health and use of healthcare services were analyzed according to the demographic and socio-economic conditions of the citizens. Specifically, the empirical analysis focuses on individual strategies related to the consumption of CAM treatments.

That spending on health has fallen off during the crisis that is amply documented by the literature. Some studies suggest that the effects of the crisis on health are more reflected in men, in terms of suicides and alcohol consumption, [21] and among young people in the 30 - 40 age brackets. These are the most vulnerable and most affected in their health by the economic crisis, probably because it steepens the already existing social gradient [11] [16]. It is known that lack of economic growth jeopardizes as well the economic welfare, bringing a dearth of material resources and consequent economic/financial insecurity, which directly reflects upon individual health [1]. Overwork, increasing unemployment, job precariousness and falling remuneration all bear directly and adversely on health.

In Italy, 298,000 families were impoverished in 2009 on account of healthcare spending, while 675,000 families had to bear a catastrophic healthcare burden [24]. According to various sources, family debt increased owing to medical outlay, especially dental work. From February to June 2014 these rose by 4.7\% [11] [25].

A drop in specialist services and medicines likewise reflects the economic crisis. Difficulty in paying the basic charge ("ticket") is a further gauge of the im- 
pact of the crisis on health: fewer services are prescribed or patients fail to go through with them [26] [27]. In Italy, the recourse to dental care has fallen off by $23.0 \%$ since 2012 [4]. Over the last year, $14.3 \%$ of people (over 14 years of age) have stopped going to the dentist although in need, and $85.0 \%$ of them have done so for financial reasons.

We have shown the data available in the foregoing sections. They reveal, among other things, how the economic crisis has curtailed CAM consumption in Italy with the trend slumped to $8.2 \%$ in 2013 [22]. The downward trend gained momentum in the period of economic crisis. Between 2005 and 2013 it roughly halved (homeopathy went from $7.0 \%$ to $4.1 \%$, phytotherapy from $3.7 \%$ to $1.9 \%$, acupuncture from $1.8 \%$ to $1.0 \%$ ). The middle classes, people in precarious jobs and men have been particularly prone to cutting CAM outlay in the period observed.

Once again it is women occupying less exalted professional positions than men who reduce their consumption of CAM, while women in jobs of intermediate status maintain their consumption over the period in question. The economic crisis has brought out the greater inequality of CAM consumption among women according to their position in the professional hierarchy.

The sharpest reduction of all on the women front is among clerical staff/ managers where the drop is 6.8 percentage points for homeopathy, followed by those on a Co.Co.Co. style work contract whose consumption of phytotherapy is down by 5.9 percentage points. Immediately after that come women, clerical workers/managers, dropping 5.7 percentage points on manual treatments.

When it comes to acupuncture, we find self-employed women decreasing their consumption by 2.5 percentage points. Female factory workers reduced significantly less on homeopathy (minus 5.3 percentage points), phytotherapy (minus 3.8 percentage points) and manual treatments (minus 4.4 percentage points), with acupuncture down by 0.7 percentage point and other forms of CAM by 0.2 percentage point.

A reduction is also noted among housewives: minus 3.4 percentage points for homeopathy, minus 3.1 percentage points for manual treatments, minus 1.9 percentage points for phytotherapy, minus 0.9 percentage points for acupuncture and minus 0.3 percentage points for the other CAMs.

Especially the women of northern Italy, traditional consumers of CAM, have signally reduced their use of such treatments.

Traditionally, the northern regions as a whole have used non-conventional medicines more than other regions, and it is there that we find the greatest contraction. Homeopathy has felt the pinch of economic crisis most, in territorial terms, since consumption went from 7 percentage points to 4.1 percentage points in the period 2005-2013. The north-eastern has been particularly hard hit by the effects of economic crisis [23].

Those who use manual treatments and homeopathy have been particularly affected by the economic crisis.

As observed in the previous paragraph, while men tend to follow the simple 
strategy of reducing consumption and going over to one type of CAM, the spending strategies of women, the elderly and minors prove more complex.

Among the elderlies who are above 70 years of age, even in times of crisis, the use of one CAM increases (respectively 69.8, 76.5 and 83.0 percentage points). However, this age bracket again decreases its pattern when it comes to double or triple CAM use.

For minors between 0 and 14 years of age, we find an increase in consumption of one CAM from 2000 to 2005 (79.7 percentage points versus 81.2 percentage points), thereafter falling to 80.7 percentage points.

Minors again increase their use of two CAMs simultaneously: from 14.9 percentage points in 2000 to 16.0 in 2005 and 17.4 in 2013.

For the latters, their parents' policy is presumably to consolidate consumption of at least one CAM and increase this, no longer to three but only to two forms of CAM simultaneously. For such people, the health capital in which to invest seems to remain central, crisis or no.

From the data available, although it may be said that crisis does also weigh on CAM users, they tend not just to reduce their health budget as users of biomedicine do [24]. Their strategy is not so much containment of cost tout court, but to pluralise their choice of CAM so as to limit the cost in part but not completely lose the health benefits. CAM users are less drastic: they may go from three to two forms of CAM for minors and one for women and the elderlies.

The increase in single-CAM use is less marked for women than for men: women go from 63.7 percentage points in 2000 to 66.2 percentage points in 2005 and 72.8 percentage points in 2013. Men single-CAM users increase from 68.1 percentage points in 2000 to 73.6 percentage points in 2005 and 79.0 percentage points in 2013.

Stepping up CAM consumption for their children even in time of crisis is a form of investment in health capital which parents are prepared to make for their offspring. The fact that elderly people increase their recourse to one form of CAM even during a crisis may be explained by their having a more stable if modest, income: their pension. They also tend to suffer from chronic conditions, which they simply have to live with, and CAM are a valid support in this.

We lack the data for building up a comparison with other countries. The impact of the economic crisis on CAM consumption has been so far an underexplored topic in scientific literature. But we may certainly conjecture that the decrease found in Italy is not just due to the waning economic resources of the middle classes, but also, and maybe especially, to the fact that Italy's National Health Service as a whole does not cover CAM treatment: only in the Region of Tuscany the above mentioned forms of CAM are covered by the regional health service, thus the private citizen only pays the sales tax on the medical prescription.

The use of CAM in Tuscany is indeed still high: 13.4\% in 2009 when the crisis was cutting in [25] [28]. It is our belief that by ensuring those services the regional health system has contained the fall in consumption in that area. 
Though limited in its data and unable to draw comparisons, our study does show the impact of the crisis on CAM users. The reduction is probably even greater, given that such forms of treatment do not come under the National Health Service. Our data do, however, suggest that CAM users are more strategic where health is at stake than is the average biomedicine user.

When all is said, though, the economic crisis has cramped citizens' health options, as the literature fully confirms [29] [30] [31]. As well as confirming the trend, our data show how difficult it is to afford forms of treatment not covered by the health system at times of economic crisis. People tighten their general health budget and the trend is particularly marked when it comes to supplementary remedies. In the circumstances, people are forced to limit the number of CAMs they use.

Monitoring such consumption may be a useful gauge of the extent to which Italy is emerging from recession. It will also in due course throw light on the consumers in question, who appear to be acting on a strategy: to keep on with CAM treatment, despite the general cut back, unlike those who only use biomedicine.

Beside well-known spending trends, this article highlights the relevance of specific management health related strategies referred to particular social groups that usually use CAM: adult women, elderly and minor. They don't reduce completely their expenditure for CAM treatments but in order to maintain the positive effects formerly obtained, continue with a less number of treatments.

The analysed data support our hypothesis that health and health seeking behaviours are greatly conditioned by socio-economic condition and by the context in which people live, thus it invite to pay more attention to the socio-demographical aspects as crucial factors in determining the consumption trends of CAM treatments in a national context.

The analysis also reveals the negative impact of the ongoing economic crisis on health (unhealthy lifestyles) and its adverse effects on health-related consumption behaviours (reluctance to apply for medical assistance) by identifying what kind of people believe that health remain a capital to maintain also in a period of economic crisis such the one we are facing lately.

Hence, the article shows how it is possible to identify segments of the population at risk, studying the inequalities in health distribution and access to services.

Furthermore, integrating this information with the sources of administrative data it could be possible to enrich the information base needed for social and health planning and promotion of public health, both nationally and locally and this yields an additional value to the analysis.

The future availability of data related to other countries would make possible an international comparison on the same subject.

\section{References}

[1] Marmot, M.G. and Bell, R. (2009) How Will the Financial Crisis Affect Health? BMJ, 338, b1314. https://doi.org/10.1136/bmj.b1314 
[2] Catalano, R., Goldman-Mellor, S., Saxton, K., Margerison-Zilko, C., Subbaraman, M., Lewinn, K. and Anderson, E. (2011) The Health Effects of Economic Decline. Annual Review of Public Health, 32, 431-450. https://doi.org/10.1146/annurev-publhealth-031210-101146

[3] Davies, R., Jones, P. and Nunez, I. (2009) The Impact of the Business Cycle on Occupational Injuries in the UK. Social Science \& Medicine, 69, 178-182. https://doi.org/10.1016/j.socscimed.2009.04.033

[4] ISTAT (2013) La Salute e il Ricorso ai Servizi Sanitari Attraverso la Crisi. Statistiche Report (Health and Use of Health Services during the Crisis. Statistical Report).

[5] De Vogli, R. and Gimmeno, D. (2009) Changes in Income Inequality and Suicide Rates after "Shock Therapy": Evidence from Eastern Europe. Journal of Epidemiology and Community Health, 63, 956. https://doi.org/10.1136/jech.2008.084079

[6] De Lago, M. (2011) Organ Donors and Transplantations Decrease in Spain, The Leading Country in Both. BMJ, 342, d242. https://doi.org/10.1136/bmj.d242

[7] McKee-Ryan, F., Song, Z., Wanberg, C.R. and Kinicki, A.J. (2005) Psychological and Physical Well-Being during Unemployment. A Meta-Analytic Study. Journal of Applied Psychology, 90, 53-76.

[8] De Vogli, R. (2013) Unemployment and Suicides during the Recession in Italy. BMJ, 347, f4908. https://doi.org/10.1136/bmj.f4908

[9] Halliday, T.J. (2014) Unemployment and Mortality: Evidence from the PSID. Social Science \& Medicine, 113, 15-22. https://doi.org/10.1016/j.socscimed.2014.04.038

[10] Tognetti Bordogna, M. (2014) From Medicalisation to Pharmaceuticalisation a Sociological Overview. New Scenarios for the Sociology of Health. Social Change Review, 12, 119-140.

[11] Kentikelenis, A., Karanikolos, M., Papanicolas, I., Basu, S., Mckee, M. and Stuckler, D. (2011) Health Effects of Financial Crisis: Omens of a Greek Tragedy. The Lancet, 378, 1457-1458.

[12] Ashton, J.R., Middleton, J.R. and Lang, T. (2014) Open Letter to Prime Minister David Cameron on Food Poverty in the UK. The Lancet, 383, 1631.

[13] Tassinari, M., Cerritelli, F. and Roberti di Sarsina, P. (2016) A Commentary on "Alternative, Complementary or Orthodox: What is Real Medicine?" European Journal for Person Centered Healthcare, 4, 472-474. https://doi.org/10.5750/ejpch.v4i3.1186

[14] Tognetti Bordogna, M. (2011) Regional Health Systems and Non-Conventional Medicine: The Situation in Italy. EPMA Journal, 2, 411-423. https://doi.org/10.1007/s13167-011-0098-6

[15] Sassatelli, R., Santoro, M. and Semi, G. (2015) Deal with the Crisis. How Does the Middle-Class Lifestyle Change. Il Mulino, Bologna.

[16] Suhrcke, M. and Stuckler, D. (2012) Will the Recession Be Bad for Our Health? It Depends. Social Science \& Medicine, 74, 647-653.

[17] ISTAT (2012) La Povertà in Italia 2011. Statistiche Report (Poverty in Italy 2011. Statistical Report). http://www.istat.it/it/archivio/66983

[18] Melucci, A. (2015) Del Prendersi Cura (About the Caring). In: Cardano, S., Manghi, M., Tognetti, M. and Vicarelli, G., Eds., La Salute per Tutti (Health for All), Franco Angeli, Milano, 115-120.

[19] Roberti di Sarsina, P. and Tassinari, M. (2016) Inclusive Healthcare, Medicine (Health Care) Focused on the Person: A Step beyond Integrative Medicine, Complementary and Alternative, Non Conventional Medicine. Current Traditional Medicine, 2, 18-21. https://doi.org/10.2174/2215083802999160722153006

[20] CENSIS (2015) 9 Million Opted out of Health Care. 
http://www.regioni.it/newsletter/n-2815/del-22-10-2015/censis-in-9-milioni-hannorinunciato-ad-una-prestazione-sanitaria-14476/

[21] Davalos, M.E., Fang, H. and French, M.T. (2012) Easing the Pain of an Economic Downturn: Macroeconomic Conditions and Excessive Alcohol Consumption. Health Econ, 21, 1318-1335. https://doi.org/10.1002/hec.1788

[22] ISTAT (2014) Condizioni di Salute e Ricorso ai Servizi Sanitari, Dati dal 1999 Al 2013 (Health Conditions and Use of Health Services in the Period 1999-2013). ISTAT, Roma.

[23] Saraceno, C. (2015) Il Lavoro non Basta (The Job Is Not Enough). il Mulino, Bologna.

[24] Costa, G., Marra, M. and Salmaso, S. (2013) La Salute ai Tempi della Crisi (Health in Times of Crisis). In: Gensini, G.F., Nicelli, A.L., Trabucchi, M. and Vanara, F., Eds., Rapporto Sanità 2013. Sistema Sanitario e Sviluppo del Paese: Alcune Specificità in Tempo di Crisi, Fondazione Smith Kline (Health Report 2013. Health System and Development of the Country. Some Specificities in Times of Crisis, Smith Kline Foundation), Il Mulino, Bologna, 35-115.

[25] CEIS (2010) Rapporto Sanità 2009. Sanità e Sviluppo Economico (Health Report 2009. Health and Economic Development). Health Communications, Roma.

[26] Terraneo, M., Sarti, S. and Tognetti Bordogna, M. (2014) Social Inequalities and Pharmaceutical Cost Sharing in Italian Regions. International Journal of Health Services, 44, 761-785. https://doi.org/10.2190/HS.44.4.e

[27] CENSIS (2016) Dalla Fotografia dell'evoluzione della Sanità Italiana alle Soluzioni in Campo. Sintesi dei Principali Risultati (Italian Health Systems: A Survey on Its Evolution. Summary of the Main Results). CENSIS, Roma.

[28] Rossi, E. (2010) Toscana: Cure Dolci Sempre sulla Cresta dell'onda (Tuscany: Delicate Treatments Always on the Footlight). Notiziario Regionale delle Medicine Complementari, 19, 2.

[29] Barr, B., Taylor-Robinson, D., Scott-Samuel, A., McKee, M. and Stuckler, D. (2012) Suicides Associated with the 2008-2010 Economic Recession in England: Time Trends Analysis. BMJ, 345, e5142. https://doi.org/10.1136/bmj.e5142

[30] Bhui, K.S., Dinos, S., Stansfeld, S.A. and White, P.D. (2012) A Synthesis of the Evidence for Managing Stress at Work: A Review of the Reviews Reporting on Anxiety, Depression, and Absenteeism. Journal of Environmental and Public Health, 2012, Article ID: 515874. https://doi.org/10.1155/2012/515874

[31] Karanikolos, M., Heino, P., McKee, M., Stuckler, D. and Legido-Quigley, H. (2016) Effects of the Global Financial Crisis on Health in High-Income Oecd Countries: A Narrative Review. International Journal of Health Services, 46, 208-240. https://doi.org/10.1177/0020731416637160 
Submit or recommend next manuscript to SCIRP and we will provide best service for you:

Accepting pre-submission inquiries through Email, Facebook, LinkedIn, Twitter, etc. A wide selection of journals (inclusive of 9 subjects, more than 200 journals)

Providing 24-hour high-quality service

User-friendly online submission system

Fair and swift peer-review system

Efficient typesetting and proofreading procedure

Display of the result of downloads and visits, as well as the number of cited articles Maximum dissemination of your research work

Submit your manuscript at: http://papersubmission.scirp.org/

Or contact jss@scirp.org 